\title{
A NEW DEVICE FOR CHARACTERISATION OF THE DRAINAGE KINETICS OF FIBROUS SUSPENSIONS UNDER GRAVITY
}

\author{
Piotr Przybysz ${ }^{1}$, Czesław Kuncewicz ${ }^{2 *}$, František Rieger ${ }^{3}$ \\ ${ }^{1}$ Lodz University of Technology, Institute of Papermaking and Printing, Wolczanska 229, 90-924 \\ Lodz, Poland \\ ${ }^{2}$ Lodz University of Technology, Faculty of Process and Environmental Engineering, Wolczanska \\ 213, 90-924 Lodz, Poland \\ ${ }^{3}$ Czech Technical University, Faculty of Mechanical Engineering, Technicka 4, 16607 Prague, \\ Czech Republic
}

\begin{abstract}
Gravity dewatering of fibrous suspension is one of basic technological operations in paper production process. Although there are numerous methods to determine dewatering of such suspensions, none of them can measure undisturbed flow of removed water. In the paper the idea and design of a new apparatus for the determination of drainage rate of fibrous suspensions is presented. The apparatus differs from other known devices by minimisation of filtrate flow resistance in the outlet part of the equipment. In the second part of the paper measurements of the drainage rate have been presented. The flow resistance of the fluid through the bottom wire screen in the device was determined. The calculated flow resistance will be used in the developed model of dynamic drainage of fibrous suspensions, which will be discussed in our following paper (Przybysz et al., 2014).
\end{abstract}

Keywords: drainage, fibrous suspensions, drainage apparatus

\section{INTRODUCTION}

Gravity drainage of fibrous suspension is an important technological operation during the papermaking process. It takes place during formation of a paper web. By applying gravity drainage, a diluted papermaking pulp suspension is directed on the wire of a paper machine where separation of excessive water under gravity takes place.

During web formation the concentration of papermaking stock increases from $0.5 \%$ up to $2 \%$. It means that for 1 ton of paper about $150 \mathrm{~m}^{3}$ of water has to be removed. During further steps - mechanical drainage and drying the amount of the removed water is about $50 \mathrm{~m}^{3}$. Taking into account the capacity of a modern paper machine, which is about 1000 tons per day, the amount of water which has to be removed is at the level of $150000 \mathrm{~m}^{3} /$ day (about $1.7 \mathrm{~m}^{3} / \mathrm{s}$ ).

In spite of great technological and economical importance of gravity drainage of fibrous suspensions a satisfactory mathematical description of the process does not exist. (Falkenberg and Belle, 2002; Mantar et al., 1995; Roschy et al., 2003; Wirth et al., 1999). One of the reasons for this situation is lack of suitable devices, which can be used for unambiguous and repeatable measurements enabling estimation of the drainage rate for papermaking pulps. Currently measurements of this parameter are 
carried out using devices for determination of retention and drainage rates. Results enable to assess particular, conventional and empirical parameters which can neither be described with the SI system (freeness) nor are accurate (drainage rate). In extreme cases, this can lead to contradictory conclusions (Wandelt and Perlińska-Sipa, 2007). This situation significantly hinders efficient modeling and as a consequence makes it difficult to carry out process optimisation.

From a historical point of view the oldest research method used for drainage determination of papermaking pulps was introduced in 1912 when M. Riegler designed an apparatus commercialised later by Schopper, which nowadays is known as Schopper-Riegler Freeness Tester (Fig. 1 left).

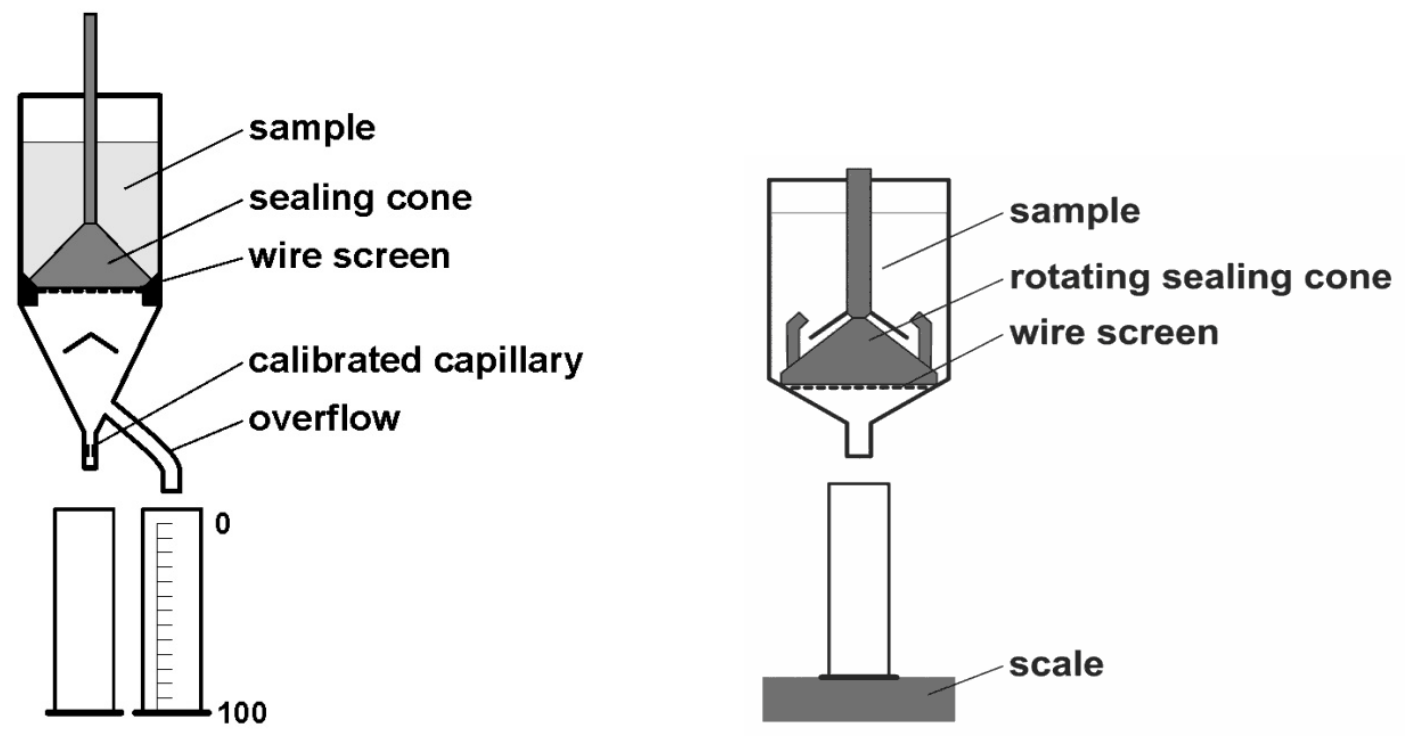

Fig. 1. Schopper-Riegler freeness tester (left) and scheme of Dynamic Filtration System

(Roschy et al., 2003) (right)

In the Schopper-Riegler device, after lowering the sealing cone, $1 \mathrm{dm}^{3}$ of fibrous suspension is placed. The concentration of this suspension is $2 \mathrm{~g} / \mathrm{dm}^{3}$. After lifting the sealing cone (Fig. 1 left), drainage of the suspension through the wire screen takes place and the filtrate is collected by the outflow cone to the vessel placed under the container with the suspension. The cone has two outlets: central, calibrated outlet and the side one used for removing surplus of the filtrate that could not pass through the central one. The construction of the Schopper-Riegler apparatus enables determination of two empirical parameters that describe drainage ability of papermaking pulps, i.e. freeness and drainability.

The freeness of a pulp [ $\left.{ }^{\circ} \mathrm{SR}\right]$ corresponds to the amount of filtrate drained off by the side overflow, while the term drainability means the time in which $700 \mathrm{ml}$ of the filtrate flows out through the side overflow while the central capillary is plugged.

Both parameters are empirical, so freeness is described by a unit invented only for the described above measurement. It should be noted that there is no relationship enabling to correlate [ $\left.{ }^{\circ} \mathrm{SR}\right]$ with any parameter being equivalent in the SI system.

Based on the methodology of the measurement, fibrous slurries that are characterised by low flow resistance during thickening have low values of Schopper-Riegler freeness [ ${ }^{\circ} \mathrm{SR}$ ]. These are slurries of unbeaten or slightly beaten fibers. Fibers in such slurries are resilient and create a highly porous fibrous structure. It should be emphasised that this apparatus is widely used today, despite its obvious deficiencies.

An alternative device for freeness and drainability determination is an apparatus called Canadian Standard Freeness Tester (TAPPI Standard T227). This device works in a similar way as that shown in 
the Fig.1 (left). The differences between these two devices are in the construction and are related mainly to a container, filter medium and the mechanism enabling fibrous suspension to drain off.

Another modified Schopper-Riegler device is Dynamic Filtration System (Roschy et al., 2003) which has only one central outflow cone. This apparatus is an important step towards adapting the SchopperRiegler device for determination of gravity drainage kinetics of fibrous suspensions. In this apparatus (Fig. 1 right), a bigger diameter of the outflow cone placed under the wire screen was applied and a scale for the gravimetric determination of the course of drainage was installed.

Readings from the scale are gathered and processed by a computer system. The final effect of these drainage measurements is a curve describing the amount of water drained off as a function of time.

The above described devices cannot be directly used for the assessment of pulp drainage rates, because of a significant converging profile of the outflow cone. In this case the rate of outflowing water from the wire screen is not the same as that of the growing amounts of water in measuring vessels placed under the device. This is an effect of additional flow resistance inside the outflow cone ending with a conduit draining off the filtrate, which has the cross-sectional area of $4.62 \mathrm{~cm}^{2}$. The obtained results cannot be regarded as being identical with the real ones which refer to drainage kinetics, i.e. obtained when free outflow of filtrate takes place. The influence of flow resistance of the elements draining off the filtrate is visible in case when pulps are characterised by a very short drainage time.

The difference in the course of the curves describing drainage in the condition of free outflow with additional flow resistance of filtrate in the outflow cone is showed in Fig. 2. A high mass flow rate of filtrate is described by the A area. Due to high flow, a momentary hold-up of a part of the filtrate in the cone takes place. In the area $\mathrm{B}$, when the flow rate of the filtrate is significantly smaller, the accumulated beforehand part of the filtrate starts to discharge. This results in an increased total outflow (measured) of the filtrate into the measuring vessel. This is the reason why in the area B an apparent increase of the filtrate flow can be observed. For low values of filtrate flow (area C) "the cone effect" does not play a significant role and the two curves overlap.
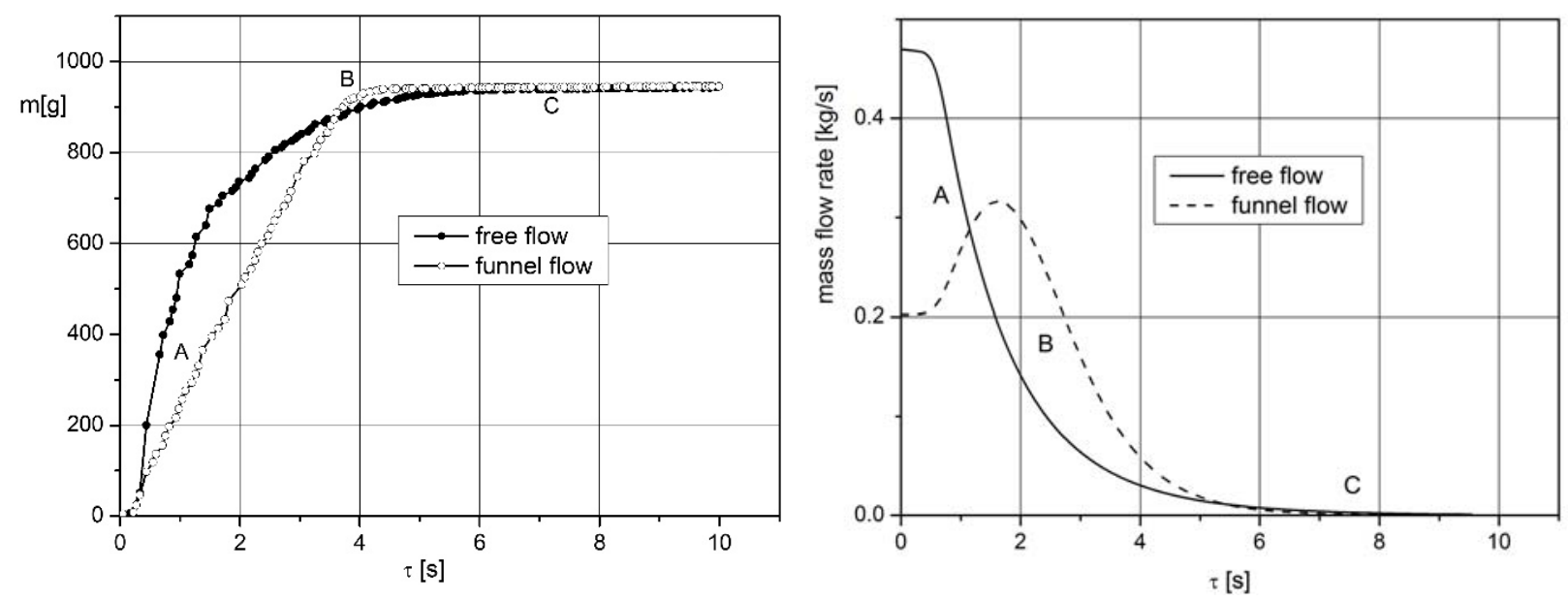

Fig. 2. Mass flowrate of the filtrate from the device for drainage determination with an additional flow resistance

The graph showing mass flow rate of the filtrate (Fig. 2 right) confirms the assumption of a negative influence of outflow resistance of filtrate caused by the outflow cone during the measurement. The maximum filtrate mass flow rate is by about 30\% smaller for the Dynamic Filtration System in comparison with a free flow (without a cone). 
Similar remarks refer to a fully automatic device - Drainage Freeness Retention (DFR-04) used for the measurements of freeness, drainage and retention of fines during gravity drainage of fibrous suspensions (Falkenberg et al., 2002).

Because of construction imperfections of the above described devices it is impossible to use them for direct measurement of drainage kinetics. The main reason for that is an additional flow resistance in outflow cones. It is obvious that they have been built for other purposes.

Taking the above results into consideration, the aim of this work was to construct a new device that enables direct measurements of the drainage rate for fibrous suspensions.

Direct measurements of the drainage rate may give a basis for the formulation of a mathematical model for the process of fiber suspension gravity drainage. This achievement would enable better management of paper web formation process and minimise its production cost. A mathematical model describing fibrous slurry drainage kinetics is presented elsewhere (Przybysz et al., 2014).

\section{MECHANISM OF GRAVITY DRAINAGE OF FIBROUS SUSPENSION}

In the free drainage process of diluted fibrous suspension across the wire screen or perforated barrier under the influence of gravitational force, the surplus of free water is removed (Przybysz and Sokołow, 2001; Przybysz, 2005). Residual water in the dewatered fibrous suspension is called gravitational water (Przybysz, 2007). This type of water includes the water bound within fibers and in fines as well as water held by surface tension forces between elements described above in the suspension under consideration.

In general, gravity drainage of fibrous suspension may proceed through thickening and/or filtration (Mantar et al., 1995). The drainage mechanism by filtration is based on a filtration bed composed of dewatered fibrous suspension on the wire. During the process, other layers of fibers and fines are deposited on the filtration bed. The thickness of the filtration bed increases along with increase in suspension concentration.

Drainage mechanism through thickening can be observed when the concentration in the whole volume of a considered suspension simultaneously increases. With the successive portions of separated water, the level of the suspension decreases until the thickened layer of the pulp remains on the wire screen only (Fig. 3 on the right).

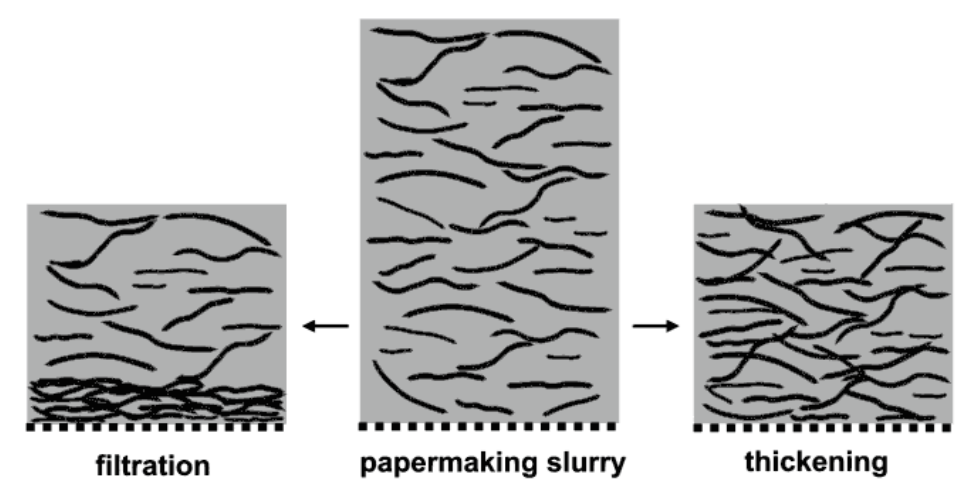

Fig. 3. Models of papermaking suspension formation mechanisms

In practice, during gravity drainage of fibrous suspension both mechanisms can be observed (filtration as well as thickening), but their influence on the process is not the same and depends on the conditions under which the process is accomplished (Britt et al., 1986). 


\section{TEST RIG}

The methods and devices used for determination of gravity drainage of fibrous suspension that have been presented in the previous chapter, cannot be applied for direct measurements of drainage rate because of excessive flow resistance in the outflow cone. This is the reason why in this paper a new equipment design has been proposed and is presented in Fig. 4.

The construction of such a device is based on the mechanism used in Schopper-Riegler apparatus. The application of typical parts commonly used in the Schopper-Riegler device facilitated standardization of the elaborated apparatus.

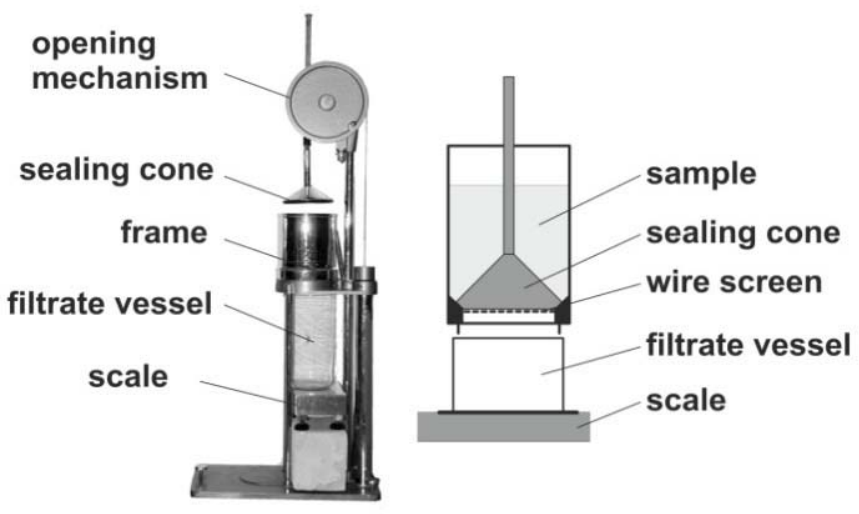

Fig. 4. Scheme and photo of new drainage tester

The constructed device (Fig. 4) consists of a metal container with a volume of $2 \mathrm{dm}^{3}$. There is a wire screen made of phosphor bronze mesh no. 120 (which corresponds to 125 micron gap size) in the bottom of the container. The wire screens as well as the fixation mechanism are typical solutions applied in the Schopper-Riegler device. There is a metal sealing cone in the container, which is used for the closing outflow of suspension across the wire screen. The sealing cone is lifted through a counterbalance placed on the device frame. The opening system which enables outflow of the suspension from the container is a standard mechanism used in the apparatus for determination of freeness. Directly under the container a ring made from plastic and rubber was immersed. The purpose of this ring is to provide a total direct discharge of the filtrate into a vessel placed under the container. The vessel with volume of $2 \mathrm{dm}^{3}$ is placed on the electronic scale, exactly under the container. The whole device is placed on a pedestal. A stable pedestal is necessary to minimise the vibration of the scale caused by the stream of separated filtrate. Scale readings were recorded on the computer (not shown in Fig. 4) 20 times per second. An additional feature of the data acquisition system is the automatic start of measurement at the same moment as the filtrate appears in the vessel on the scale.

The constructed unique device enables investigation of the course of the drainage process of the suspension with a volume of $1 \mathrm{dm}^{3}$ for the concentration in the range of 0 to $0.5 \%$ corresponding to paper basis weight up to $600 \mathrm{~g} / \mathrm{m}^{2}$.

\section{A MODEL OF THE FLUID FLOW THROUGH THE WIRE SCREEN OF THE TESTING CONTAINER}

In the presented device the fluid flow through the wire screen due to hydrostatic pressure is decreasing because the driving force of the process has monotonically lower values in time. This situation is schematically shown in Fig. 5. 
In general, water has to overcome two different types of flow which contribute to the total $\Delta p$. The first one is the resistance of flow through the thickening pulp, $\Delta p_{\text {pulp }}$, and the second one is the flow

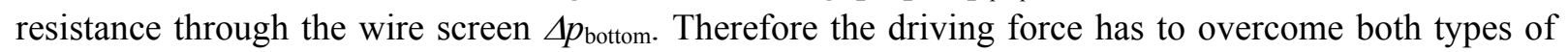
flow resistance

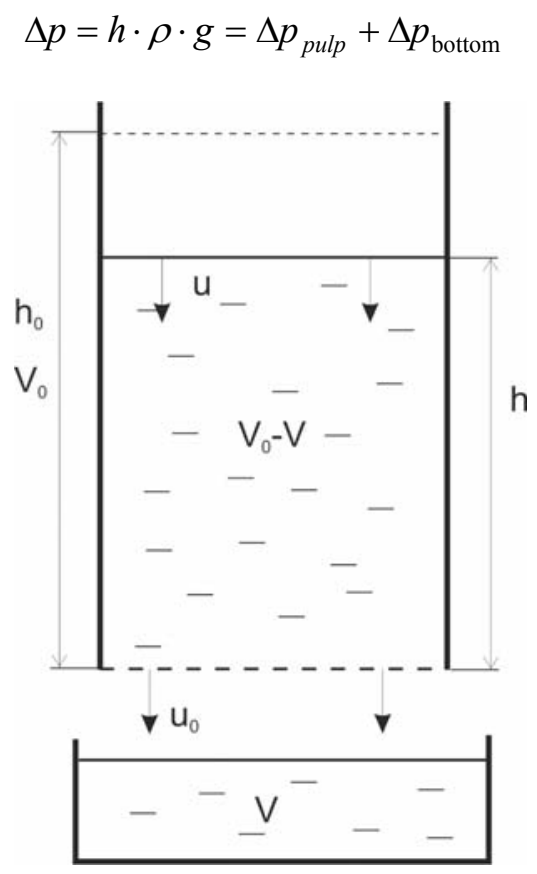

Fig. 5. Simplified scheme of experimental apparatus

Taking thickening into consideration, the value of the first component, $\Delta p_{\text {pulp }}$, on the right hand side of equation (1) is of primary importance, because the value of $\Delta p_{\text {bottom }}$ depends only on the construction of the device. From the technical point of view, the only measurable value can be found on the left side of

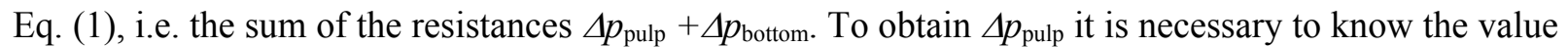

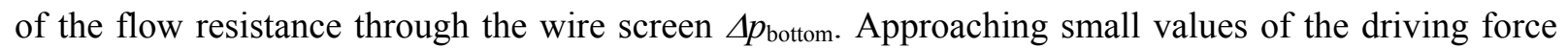
these two types of flow resistances are comparable, therefore the knowledge of the $\Delta p_{\text {bottom value plays }}$ an important role in the considered case.

Taking into consideration the variability of these parameters during the flow of suspensions some significant problems in the assessment of the flow resistance $\Delta p_{\text {bottom }}$ through the wire screen were encountered. In order to determine the $\Delta p_{\text {bottom, }}$ and on this basis to specify the resistance coefficients of wire a dynamic model of the process should be developed. Based on the information presented in this paper, the following part of the work (Przybysz et al., 2014) it will demonstrate how to calculate flow resistance through the thickening pulp only.

To assess the flow resistance $\Delta p_{\text {bottom}}$, clear fluids of different viscosity were used. The absence of pulp excludes the presence of $\Delta p_{\text {pulp }}$ resistance. In that case the whole driving force triggers the flow of the fluid through free spaces in the wire screen which means $\Delta p=\Delta p_{\text {bottom. }}$

The flow resistance through the wire screen can be taken as a local resistance in which this value (Serwiński, 1982) can be described by a classic equation (2)

$$
\Delta p=\zeta \frac{u_{0}^{2}}{2} \rho_{F}
$$

where $\zeta$ means the local resistance coefficient and is a function of Reynolds number. 
Functional dependency $\zeta=f(R e)$ depends on the range of fluid motion. In the present paper even at the highest flow rate through the wire screen and for clear water the values of Reynolds number defined by Eq. (3) are in the range of $R e=20-30$. This corresponds to a laminar flow, for which the coefficient of the local resistance $\zeta$, according to Eq. (4), is inversely proportional to the Reynolds number.

$$
\begin{gathered}
\operatorname{Re}=\frac{u_{0} \cdot d_{0} \cdot \rho_{F}}{\eta}=\frac{u \cdot d_{0} \cdot \rho_{F}}{\beta \cdot \eta} \\
\zeta=\frac{a}{\operatorname{Re}}
\end{gathered}
$$

The value of constant, $a$, in Eq. (4) is characteristic for a defined geometry of the wire screen. Substituting Eqs. (3) and (4) into Eq. (2), and taking into consideration that for the experimental conditions the driving force is $\Delta p=h \cdot \rho_{F} \cdot g$, we obtain

$$
h \cdot \rho_{F} \cdot g=\frac{a \cdot \eta}{2 \beta \cdot d_{0}} u
$$

For an unsteady liquid flow its superficial velocity, $u$, resulting from a decreasing liquid level in the cylinder is described by Eq. (6), and the current height of the fluid can be calculated from Eq. (7) (cf. Fig. 5)

$$
\begin{aligned}
& u=\frac{d V}{A \cdot d \tau} \\
& h=\frac{V_{0}-V}{A}
\end{aligned}
$$

Substituting Eqs. (6) and (7) into Eq. (5), one can obtain Eq. (8) which after integration within the limits $0-V$ and $0-\tau$ yields Eq. (9)

$$
\begin{gathered}
\frac{d V}{V_{0}-V}=\frac{2 \beta \cdot d_{0} \cdot \rho_{F} \cdot g}{a \cdot \eta} \cdot d \tau \\
\ln \left(\frac{V_{0}}{V_{0}-V}\right)=\frac{2 \beta \cdot d_{0} \cdot \rho_{F} \cdot g}{a \cdot \eta} \tau
\end{gathered}
$$

When $a=$ const the right side of Eq. (9) is constant and can be denoted as $k$

$$
\frac{2 \beta \cdot d_{0} \cdot \rho_{F} \cdot g}{a \cdot \eta}=k=\text { const. }
$$

Finally we get a simple form of Eq. (11)

$$
\ln \left(\frac{V_{0}}{V_{0}-V}\right)=k \cdot \tau
$$

After taking into consideration the definition of the volume fraction $x$, Eq. (11) takes the following form

$$
\ln \left(\frac{1}{1-x}\right)=k \cdot \tau
$$

If the earlier assumptions are true then according to Eq. (12) experimental points plotted in the form of $\ln [1 /(1-x)]$ vs. $\tau$ should be located along a straight line passing thought the origin. The slope of this line may be denoted as a rate constant $k$. 


\section{EXPERIMENTAL RESULTS}

Measurements were carried out on testing equipment shown in Fig. 4. Aqueous solutions of potato syrup (starch syrup) were used as the testing liquids. Physical properties of these solutions are shown in Table 1. In the test apparatus a wire screen number 120 was used, corresponding to the size of a single hole $d_{0}=0.2 \mathrm{~mm}$.

Table 1. Physical-chemical properties of potato syrup solutions

\begin{tabular}{|c|c|c|}
\hline No. of solution & $\rho_{F}\left[\mathrm{~kg} / \mathrm{m}^{3}\right]$ & $\eta[$ Pas $]$ \\
\hline 1 & 1004 & 0.0041 \\
\hline 2 & 1179 & 0.013 \\
\hline 3 & 1258 & 0.043 \\
\hline 4 & 1284 & 0.085 \\
\hline
\end{tabular}

Fig. 6 (left) shows a typical curve $V=f(\tau)$ obtained during the measurements. It is easy to notice that at the beginning of the flow, the volume fraction $x$ of liquid that has passed through the wire screen is growing very quickly, but as time goes on with a decreasing driving force an increase in the value of $x$ is gradually smaller.

Similar curve shapes were also obtained in other cases. During measurements the liquid flow through the wire screen was quite stable. Only at the beginning of the flow, for a time shorter than $0.5 \mathrm{~s}$, when the driving force is the greatest, a surprisingly little increase of $x$ was observed. It can only be explained by he specific technical features of the testing devices. The opening of the sealing cone blocking the flow does not proceed immediately. During lifting of the sealing cone a negative pressure appears at the bottom of the cylinder reducing the driving force and resulting in diminishing of the liquid flow to very small values. On the basis of analysis of all curves plotted in coordinates $x$ vs. $\tau$ it was established that the sealing cone opening time depends on liquid viscosity and its value changes from $0.2 \mathrm{~s}$ for the smallest viscosity to $0.6 \mathrm{~s}$ for the highest viscosity.

Analysis of the charts showing $x=f(\tau)$ revealed that the smaller the liquid viscosity the faster testing points converge to the asymptote $x=1.0$. This observation is in line with the phenomena perceived in the process.
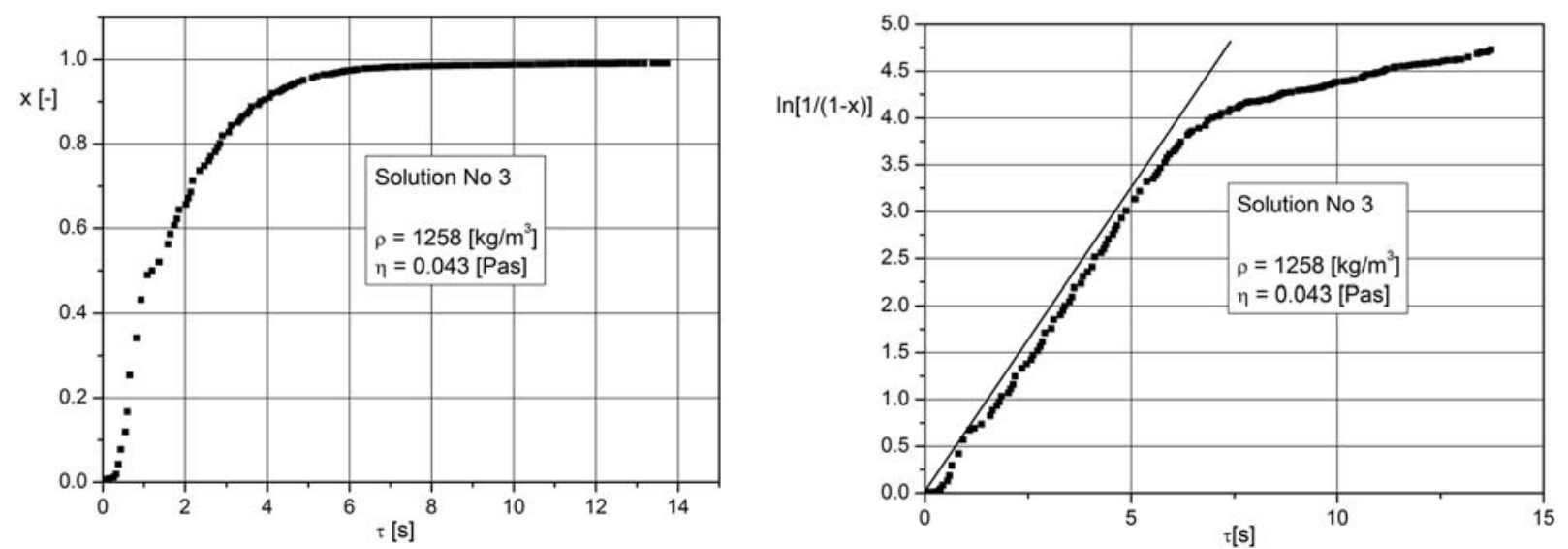

Fig. 6. Outflow of the liquid through the wire screen

Fig. 6 (right) shows the same data points as in Fig. 6 (left) but in a semi-logarithmic coordinate system. Three conclusions can be derived from Fig. 6 (right). Firstly, the figure reveals that the opening time (time delay) of the sealing cone should be taken into consideration. Secondly, after accounting for 
delay time the experimental points will probably produce a straight line passing through the origin of the coordinate system. This would confirm feasibility of the flow model described in the previous point. Thirdly - for times equal to about $6-7 \mathrm{~s}$ the $x$ is equal to 0.98 and the proposed flow model will not be valid for the time of experiments greater than $6 \mathrm{~s}$. The boundary value of $\mathrm{x}=0.98$ was established on the basis of Fig. 6 (right). For time $\tau=6-7 \mathrm{~s}$ a distinct change of slope of the line occurs which means a change in the mechanism of drainage. Time $\tau=6$ s corresponds to $x=0.98$. The same boundary values $x$ were also obtained for other solutions. Probably adhesive forces between the liquid and the wall of the cylinder may start to play a role. The final $2 \%$ of the liquid flows down very slowly on the wall of the container and further under the measuring cylinder. Identical observations were made in other cases.

From the practical point of view during analysis of each testing series the delay time should be accounted for and only points from the interval $x=0-0.98$ should be taken into consideration.
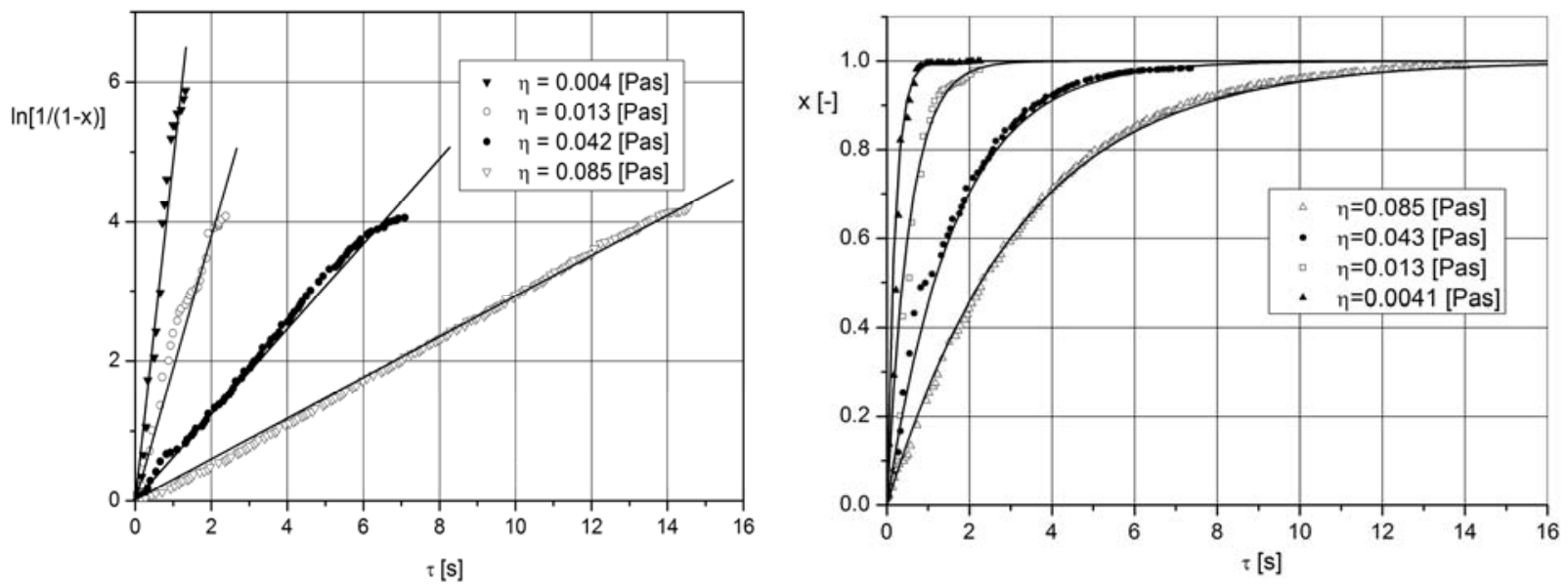

Fig. 7. The velocity of liquid outflow from graduated cylinder

Fig. 7 (left) shows a semi-logarithmic configuration of the experimental data points from the range of $x=0-0.98$ (the delay time was taken into account) for liquids of different viscosity. As seen in all cases, straight lines were obtained with different slopes of lines passing through the origin. The highest slope of curve (the fastest outflow) was obtained for the liquid of the smallest viscosity. The experimentally estimated values of the rate constant $k_{\exp }$ from Fig. 7 (left) are listed in the second column of Table 2.

Table 2. Constants of outflow velocities $k[1 / \mathrm{s}]$ for particular liquids

\begin{tabular}{|c|c|c|c|c|}
\hline$\eta[\mathrm{Pas}]$ & $k_{\exp }[1 / \mathrm{s}]$ & $a_{\exp }[-]$ & $a_{a v}[-]$ & $k_{\bmod }[1 / \mathrm{s}]$ \\
\hline 0.0041 & 5.12 & 131.3 & & 5.00 \\
\hline 0.013 & 1.86 & 133.8 & \multirow{2}{*}{135} & 1.84 \\
\hline 0.043 & 0.617 & 132.5 & & 0.606 \\
\hline 0.085 & 0.292 & 141.5 & & 0.306 \\
\hline
\end{tabular}

In the third column of Table 2 values of $a_{\exp }$ are presented. They were calculated from Eq. (10) using experimental constants $k_{\exp }$. It can be concluded that the values of $a_{\exp }$ do not significantly change. If $a=135$ is taken as an average value for all liquids then $a$ in Eq. (4) can also be assumed to be a constant for the applied bottom wire screen. This will be the only constant characterising the flow resistance through the bottom wire screen regardless of viscosity and density of the liquid. 
On the basis of these considerations a model value of the rate constant $k_{\text {mod }}$ in Eq. (10) can be calculated. These values are shown in the last column of Table 2. The difference between the experimental values of the constant $k_{\text {exp }}$ and those of the model $\left(k_{\text {mod }}\right)$ equals on average $2.9 \%$.

If Eq. (12) is transformed into Eq. (13), it enables to plot model curves $x=f(\tau)$ and allows to compare them with the curves obtained from the experimental points.

$$
x=1-\exp \left(-k_{\exp } \cdot \tau\right)
$$

Fig. 7 (right) shows a comparison of model and experimental values of the volume fraction of the outflowing liquid, $x$. A satisfactory agreement was obtained.

It should be noted that all theoretical curves showed in Fig. 7 (right) were obtained with only the average constant $a=a_{a v}=135$ based on Fig. 7 (left). The value $a=a_{a v}=135$ can be compared with similar constant values determined in other tests. In the paper of Kiljański and Dziubiński (1996) flow resistance of a molten polymer through a net mesh made of very thin wires forming a square mesh were carried out. The constant $a=62$ obtained in that paper is less than half of the value determined in our paper. It should be considered that liquid flow through a net mesh made of circular wires involves smaller flow resistance than that occurring through an opening with sharp edges.

Secondly, in the paper by Britt et al. (1986) the wire diameter is used in Reynolds number definition instead of the opening diameter as it is in the presented case. For low values of the free area of the mesh in the bottom wire screen, the distance between adjacent wires is much less than the mesh itself. Hence, the Reynolds number value calculated with the diameter of mesh, $d_{0}$, is higher in comparison with the Reynolds number calculated with the space between mesh (wire diameter).

Also in other papers (Chhabra and Richardson, 1985; Das and Chhabra, 1989; Ehrhardt, 1983) regarding flow resistance through a wire screen, the values of this constant vary from 49 to 65 . Taking into consideration differences in constructions of these two elements through which the liquid flows and different definitions of the Reynolds number, the value of constant $a$ in Eq. (4) can be regarded as reasonable.

The presented paper is a preliminary step for elaborating a model of gravity drainage of diluted solutions containing fibrous suspensions (Przybysz et al., 2014). The results of this work enable the elimination of flow resistance through the bottom wire screen in papermaking machine $\left(\Delta p_{\text {bottom }}\right.$ in Eq. (1)) from theoretical deliberations.

\section{CONCLUSIONS}

- During measurements of gravitational liquid flow through a wire screen in a device based on the Schopper-Riegler apparatus, time delay in a range of $0.2-0.6 \mathrm{~s}$ in the liquid flow was observed. It was caused by a process of lifting the sealing cone in the cylinder.

- Laminar gravitational flow rate through a wire screen can be described by classic equations of fluid mechanics.

- Good agreement between the experimental values of the volumetric flow rate through a wire screen and the values obtained from the elaborated model may be helpful in determination of the liquid flow resistance during pulp thickening process.

- From the analysis of the measuring device performance it can be concluded that the flow resistance is identical with that found for wire screens. Hence, unlike in other measuring devices, in the present case an additional flow resistance caused by technical parameters of the device practically does not exist. 
The authors gratefully acknowledge that this work was financially supported by the project LIDER/042/407/L-4/12/NCBR/2013 funded by National Center for Research and Development (Poland) and project no. W-10/1/2014/Dz. St.

\section{SYMBOLS}

$\begin{array}{ll}A & \text { cross section of the whole cylinder, } \mathrm{m}^{2} \\ A_{0} & \text { cross section area of the openings in wire screen, } \mathrm{m}^{2} \\ V & \text { volume of the liquid flowing out from the cylinder, } \mathrm{m}^{3} \\ V_{0} & \text { initial liquid volume in the cylinder, } \mathrm{m}^{3} \\ a & \text { constant in Equation }(4),- \\ d & \text { cylinder diameter, } \mathrm{m} \\ d_{0} & \text { diameter of holes in the wire screen, } \mathrm{m} \\ g & \text { gravity, } \mathrm{m} / \mathrm{s}^{2} \\ h & \text { height of the liquid in the cylinder, } \mathrm{m} \\ h_{0} & \text { initial height of the liquid in the cylinder, } \mathrm{m} \\ k & \text { rate constant, } 1 / \mathrm{s} \\ p & \text { pressure, } \mathrm{N} / \mathrm{m}^{2} \\ u & \text { rate of the decreasing of liquid surface, } \mathrm{m} / \mathrm{s} \\ u_{0} & \text { rate of the liquid in mesh, } \mathrm{m} / \mathrm{s} \\ x & \text { volumetric fraction of the liquid flowing out of the cylinder }=V / V_{0},- \\ \beta & \text { free surface coefficient }=A_{0} / A=u / u_{0},- \\ \zeta & \text { local drag coefficient, }- \\ \rho_{F} & \text { liquid density, } \mathrm{kg} / \mathrm{m}^{3} \\ \tau & \text { time, } \mathrm{s} \\ \eta & \text { dynamic viscosity, Pa } \cdot \mathrm{s}\end{array}$

\section{REFERENCES}

Britt K.W., Unbehend J.E., Shirdhran R., 1986. Observations on water removal in papermaking. TAPPI, 69, 7, 76. Chhabra R.P., Richardson J.F., 1985. Flow of liquids through screens: relationship between pressure drop and flow rate. Chem. Eng. Sci., 40, 313-316. DOI: 10.1016/0009-2509(85)80072-5.

Das S., Chhabra R.P., 1989. A note for very low Reynolds number fluid flow through screens. Chem. Eng. Process, 25, 159-161. DOI: 10.1016/0255-2701(89)80006-6.

Ehrhardt G., 1983. Flow measurements for wire gauzes. Int. Chem. Eng., 23, 455-465.

Falkenberg W., Belle J., 2002. Entwicklung und Anwendung einer neuen und schnellen LaborRetentionsmessung. Wochenblatt für Papierfabrication, 132, 22,1412-1422.

Kiljański T., Dziubiński M., 1996. Resistance to flow of molten polymers through filtration screen. Chem. Eng. Sci., 51, 4533-4536. DOI: 10.1016/0009-2509(96)00295-3.

Mantar E., Co A., Genco J.M., 1995. Drainage characteristics of pulp slurries under dynamic conditions. J. Pulp Pap. Sci., 21, 2, J44-J50.

Przybysz K., 2005. Klasyfikacja wody zawartej w papierniczych masach włóknistych i wytworach papierniczych. Przeglad Papierniczy, 61, 1, 41.

Przybysz K., 2007. Klasyfikacja wody zawartej w papierniczych masach włóknistych. Cz. II. Woda sklarowana i sedymentacyjna. Przeglad Papierniczy, 63, 2, 113.

Przybysz P., Kuncewicz Cz., Rieger F., 2014. Gravity drainage kinetics of papermaking fibrous suspension. Chem. Process Eng., 35, 421-434. DOI: 10.2478/cpe-2014-0032.

Przybysz K., Sokołow W., 2001. Uwagi o budowie i osobliwych właściwościach wody. Cz. I. Właściwości wody i hydrolowe teorie jej struktury. Przeglad Papierniczy, 57, 12, 743. 
Roschy A., Fischer S., Kleemann S., 2003. Vergleich moderner Wet-End Methoden zur Bestimmung von Entwässerung und Retention im Labormaßstab. Wochenblatt für Papierfabrication, 130, 18, 1187-1196.

Serwiński M., 1982. Zasady inżynierii chemicznej, WNT, Warszawa.

TAPPI Standard T227 “Freeness of pulp (Canadian standard method)" official test method 1985, revised 1999.

Wandelt P., Perlińska-Sipa K., 2007. Badanie odwadnialności makulaturowych mas papierniczych i wpływu na nią frakcji drobnej. Przegląd Papierniczy, 63, 7, 547.

Wirth B., Gralke R., Fisher K., Kleemann S., 1999. Labormethoden zur Bestimmung von Retention und Entwässerung. Wbl. Papierfabr., 127, 17, 1100 -1107.

Received 08 September 2013

Received in revised form 04 July 2014

Accepted 24 July 2014 